\title{
ACTIVE STRUCTURAL CONTROL OF FRAME SEISMIC VIBRATIONS
}

\author{
Dejan Lj. Milutinovic ${ }^{1}$ \\ Slobodan B. Furundzic ${ }^{2}$ \\ ${ }^{1}$ Mihajlo Pupin Institute, Volgina 15, Belgrade, Yugoslavia \\ ${ }^{2}$ Advanced School of Civil Engineering and Geodesy, \\ Hajduk Stankova 2, Belgrade, Yugoslavia \\ e-mail:edejan@afrodita.rcub.bg.ac.yu
}

\begin{abstract}
A theory of frame beam displacement control by active tendons is presented in this paper. A dynamic loading is horizontal displacement of supports, such as one occurring during an earthquake. The frame is approximated by a single-degree-offreedom system. The state equation is obtained from the system equation of motion. The optimal control is applied by an integral quadratic criterion. A control numerical example of a reinforced concrete frame, such as one of a turbo-alternators foundation, is presented. The accelerogram of the Petrovac earthquake recorded in Montenegro is used as base excitation. The system responses with and without control are compared. After that, the same system responses to a rectangular pulse base excitation are parametricaly analysed. The numerical results obtained indicate that frame seismic vibrations can be considerably decreased by the active control.
\end{abstract}

Keywords: active structural control, structural dynamics, concrete frame vibrations

\section{INTRODUCTION}

Structural control, where structural dynamics (Clough and Penzien, 1975) problems are analyzed by control theory (Barnett, 1975), is a new interdisciplinary branch of civil engineering (Domke et al., 1981). Starting from the pioneer concept (Yao, 1972), active structural control is intensively investigated both theoretically and experimentally (Spencer and Sain, 1997).

A civil engineering structure starts to vibrate when exposed to strong dynamic loading, such as ground motion during an earthquake. The aim of structural control, which provides the control system attached to the structure (Fig. 1), is to reduce unwanted structural vibrations. As well, the active structural control demands external energy supply.

The steel frame control testing (Chung et al., 1988) inspired the authors to analyze numericaly an active control of a concrete foundation frame with real dimensions. A rectangular puls as dynamic base accelerattion is studied elswhere (Furundzic and Milutinovic, 1998).
This paper presents the active control by tendon force of a frame exposed to supports motion and gives the numerical example of a frame response to the Petrovac earthquake recorded in Montenegro.

\section{DYNAMIC MODEL}

A fixed frame (Fig. 2) stiffened by two active tendons (Chung et al., 1988) and exposed to dynamic horizontal displacement of supports is observed. The mass concentrated in stiff frame beam, the laterally flexible columns and the viscous damping are assumed. A dynamic model of the frame is a single degree of freedom system (SDFS). For this system, applying D'Alambert principal, the differential equation of motion is:

$$
m \ddot{v}(t)+c \dot{v}(t)+k v(t)=-(2 \cos \theta) u(t)-m \ddot{v}_{g}(t)
$$

where: $m$ - mass, $c$ - damping, $k$ - stiffness of frame, $v$ - relative horizontal displacement of frame beam, $u$ active force in tendon, $\theta$ - angle between tendon and horizon, $\ddot{v}_{g}$ - horizontal ground acceleration, $t$ time. With Eq. (1), initial conditions are:

$$
v(0)=v_{0} ; \quad \dot{v}(0)=\dot{v}_{0}
$$


When the natural frequency $(\omega)$ and the damping coefficient $(\zeta)$ are determined:

$$
\omega=\sqrt{k / m} ; \quad \zeta=c /(2 m \omega)
$$

from Eq. (1) follows:

$$
\ddot{v}+2 \zeta \omega \dot{v}+\omega^{2} v=-\left(2 m^{-1} \cos \theta\right) u(t)-\ddot{v}_{g}(t)
$$

The state variable $\mathbf{x}$ is adopted as vector:

$$
\mathrm{x}=\left[\begin{array}{l}
\dot{v} \\
v
\end{array}\right]
$$

Eq. (4) gives the matrix differential state equation:

$$
\dot{\mathbf{x}}(t)=\mathbf{A x}(t)+\mathbf{B} u(t)+\mathbf{G} \ddot{v}_{g}(t)
$$

$\mathbf{A}=\left[\begin{array}{cc}-2 \zeta \omega & -\omega^{2} \\ 1 & 0\end{array}\right] \mathbf{B}=\left[\begin{array}{c}-2 m^{-1} \cos \theta \\ 0\end{array}\right] \mathbf{G}=\left[\begin{array}{c}-1 \\ 0\end{array}\right]$

With Eq. (6), respecting Eqs. (2) and (5), initial condition is:

$$
\mathbf{x}(0)=\mathbf{x}_{0}
$$

It is easy, according to Eq. (5), to find displacement:

$$
\begin{aligned}
& v(t)=\mathbf{C x}(t) \\
& \mathbf{C}=\left[\begin{array}{ll}
0 & 1
\end{array}\right]
\end{aligned}
$$

The same vibration problem is formulated first with Eqs. (1) and (2), and than with Eqs. (6) and (8). The frame deformation control aim is, using measurements and feed-back (Barnett, 1975), to reduce frame beam displacement by tendon force dynamic change.

\section{CONTROL SYSTEM}

The plane frame with an active control system is presented (Fig. 3). The control system essential parts are: sensor, controller, and actuator.

The sensor measures the frame beam horizontal relative displacement and velocity, which are structural output. The controller is usually a computer, which, applying the control algorithm, calculates the signal of the demanded active force. The actuator is an electro-hydraulic servomechanism (Domke et al., 1981), which produces the calculated active force in tendons.

\section{OPTIMAL CONTROL}

The frame control (Fig. 3) should be optimal. This task can be, relatively simply, solved by the linear optimal control theory applying the integral quadratic criterion (Barnett, 1975).

The controller (Fig. 3) determines the demanded active force $(u)$ on the base of frame displacement $(v)$ and velocity $(\dot{v})$, independently from supports acceleration $\left(\ddot{v}_{g}\right)$. Therefore the control algorithm is, respecting Eqs. (6) and (8), designed for a system with the following condition:

$$
\dot{\mathbf{x}}(t)=\mathbf{A x}(t)+\mathbf{B u}(t), \quad \mathbf{x}(0)=\mathbf{x}_{0}
$$

where $\mathbf{x}, \mathbf{A}, \mathbf{B}$ are defined with Eqs. (5) and (7), respectively, and where active force vector $\mathbf{u}(t)$ has one element $\mathrm{u}(t)$.

The active force $\mathbf{u}(t)$ should be, on the base of measured structural response $\mathbf{x}(t)$, determined so that the scalar functional:

$$
I(\mathbf{u})=\int_{0}^{\infty}\left[\mathbf{x}^{T} \mathbf{Q} \mathbf{x}+\mathbf{u}^{T} \mathbf{R} \mathbf{u}\right] d t
$$

is minimal for the condition given with Eq. (11). In Eq. (12), where the letter $T$ stands for transposition, the square matrices $\mathbf{Q}$ and $\mathbf{R}$ are the weighting matrices. If matrix $\mathbf{Q}$ elements are taken big, then the priority is given to decreasing of response $(\mathbf{x})$, and not to decreasing of active force (u). The opposite stands, if matrix $\mathbf{R}$ elements are taken big.

In other words, according to the control theory, the control force $\mathbf{u}(t)$ has to be on the base of measured output $\mathbf{x}(t)$ determined so that the index performance $I(\mathbf{u})$ defined by the integral square criterion Eq. (12) is minimal, while the condition (11) is fulfilled for $\mathbf{x}(t)$ and $\mathbf{u}(t)$.

The solution of problem defined with Eqs. (12) and (11) is (Barnett, 1975) the active force:

$$
\mathbf{u}(t)=-\mathbf{R}^{-1} \mathbf{B}^{T} \mathbf{P} \mathbf{x}(t)
$$

In the control low Eq. (13) appears matrix $\mathrm{P}$ obtained as the solution of matrix algebraic Riccati equation:

$$
\mathbf{A}^{T} \mathbf{P}+\mathbf{P A}-\mathbf{P} \mathbf{B} \mathbf{R}^{-1} \mathbf{B}^{T} \mathbf{P}+\mathbf{Q}=0
$$

Instead a tendon displacement (Chung et al.,1988), a tendon force, as physical quantity close to structural engineers, is used in this paper. The active force in the tendon of frame, i.e. the control low in feed-back, is sought in the linear form:

$$
u(t)=k_{1} v(t)+k_{2} \dot{v}(t)
$$

where the coefficients $k_{1}$ and $k_{2}$ are such, that minimal should be the functional:

$$
I^{*}(\mathrm{u})=\int_{0}^{\infty}\left[\frac{1}{2} k v^{2}+\frac{\beta}{2} k\left(\frac{u}{k}\right)^{2}\right] d t
$$

where: $k$-stiffness of frame, $\beta$-weighting factor. Here introduced functional Eq. (16), which is different than functional used by Chung et al. (1988), may be written in another form:

$$
I^{*}(\mathrm{u})=\frac{1}{2 k} I(\mathrm{u})
$$

where adopted novel functional is:

$$
I(\mathrm{u})=\int_{0}^{\infty}\left[k^{2} v^{2}+\beta u^{2}\right] d t
$$

This novel functional Eq. (18) is more convenient to use as the integral square criterion, than the functional Eq. (16) introduced firstly. The comparison of functionals Eqs. (12) and (18) gives the relations: 


$$
\mathbf{Q}=\left[\begin{array}{cc}
0 & 0 \\
0 & k^{2}
\end{array}\right] ; \quad \mathrm{R}=[\beta] ; \quad \mathbf{x}=\left[\begin{array}{l}
\dot{v} \\
\boldsymbol{v}
\end{array}\right] ; \quad \mathbf{u}=[u]
$$

The linear form Eq. (15), but for tendon displacement, and the functional different than Eq. (16) were allready investigated (Chung et al., 1988).

The integral square criterion Eq. (18), which presents novelty of this paper, contains two partial goals. A compromise between vibrations and, on the other side, demanded control force is predetermined by giving value to factor $\beta$. If $\beta$ is big, the active force is smaller, but the vibrations are bigger. If $\beta$ is small, the opposite stands. For $\beta=\infty$ is the case of frame without control.

The problem of finding gains $k_{1}$ and $k_{2}$ in Eq. (15) is a standard problem in linear optimal control theory (Barnett, 1975). From Eqs. (15), (18), (19) and (14), the following optimal coefficients are obtained:

$$
k_{1}=\frac{2 m^{-1} \cos \theta}{\beta} p_{11} ; k_{2}=\frac{2 m^{-1} \cos \theta}{\beta} p_{12}
$$

where $p_{11}$ and $p_{12}$ are elements of the square matrix $P$, which has second order and satisfies Eq. (14)

\section{NUMERICAL EXAMPLE}

A concrete frame machine foundation (Fig. 4) allows easier service (Savinov, 1979). We suppose that each transversal frame of such foundation is diagonally stiffned by active tendons and that foundation is exposed to horizontal earthquake in transversal direction. The foundation middle transversal frame (Fig. 5) with active tendons and given geometry (Fig. 6) exposed to supports motion due to an earthquake is observed. The active control task is foundation vibrations reduction.

\subsection{Concrete Frame}

In Table 1 dynamic characteristics of the concrete frame (Fig. 6) as SDFS are given. The lateral stiffness $(k)$ is (Beton Kalender, 1979):

$$
k=\frac{12 E I_{s}}{H^{3}} \cdot \frac{6 \alpha+1}{3 \alpha+2} ; \quad \alpha=\frac{I_{p}}{I_{s}} \frac{H}{L}
$$

where: $E$ - elasticity module of concrete, $I_{p} / I_{s}$ inertia moment of beam / column, $H / L$ - height / span of frame.

\subsection{The Petrovac earthquake accelerogram}

The Petrovac earthquake accelerogram (Fig. 7), recorded on 15th April 1979 in Montenegro, had long duration (of 28 seconds).

\subsection{Control Algorithm}

For the concrete frame dynamic model (Table 1), the control algorithm is designed using the integral square criterion Eq. (18). From measured displacement $v(t)$ and velocity $\dot{v}(t)$, the control algorithm determines control force $u(t)$ in tendons by linear low Eq. (15), where coefficients $k_{1}$ and $k_{2}$ are such that functional Eq. (18) is minimal.

\subsection{Displacement and Control Force Histories}

The Petrovac earthquake accelerogram record is used for the frame dynamic analyses.

Figs. 8, 9 and 10, respectively, for two values of weighting factor $\beta$ show history of displacement, acceleration and active force, respectively.

The displacement history (Fig. 8) clearly indicates that the examined systems with the active control $(\beta=1)$ have smaller displacements than the system without control $(\beta=\infty)$.

Table 2 shows not only the values of maximum displacement $\left(v_{\max }\left(t_{v}\right)\right)$ and maximum active force $\left(u_{\max }\left(t_{w}\right)\right)$ in tendon, followed by corresponding times $\left(t_{v}\right.$ and $\left.t_{u}\right)$, but also corresponding values of the coefficients $\left(k_{l}, k_{2}\right)$ in linear control low Eq. (1). When the weighting factor $\beta$ decreases, then maximum displacement also decreases, but maximum active force increases (Fig. 10), what requires fast change of this force.

\subsection{Weighting Factor $\beta$ Effect}

For parametric analysis a rectangular pulse (Table 1), with intensity $\left(\ddot{v}_{g}=1 \mathrm{~m} / \mathrm{s}^{2}\right)$ equal to $1 / 10$ of gravity but of short duration $\left(t_{g}=0,1 \mathrm{~s}\right)$, is adopted as horizontal acceleration of supports.

Fig. 11 shows the weighting factor $\beta$ influence on the ratio of natural frequency with control $\left(\omega_{\beta}\right)$ and without control $(\omega)$, as well as Fig. 12 shows the weighting factor $\beta$ influence on the ratio of damping factor with control $\left(\zeta_{\beta}\right)$ and without control $(\zeta)$.

It is clearly evident from Fig. 11 that the influence of weighting factor $(\beta)$ on the ratio of natural frequencies $\left(\omega_{\beta} / \omega\right)$ is unimportant, and from Fig. 12 that the same influence on the ratio of damping factors $\left(\zeta_{\beta} / \zeta\right)$ is important. 


\section{CONCLUSIONS}

The active control by tendon force of frame exposed to seismic dynamic motion of its supports is formulated by the novel criterion Eq. (18), and the numerical example of optimal control is presented.

The histories of displacement and active force in tendons approve that the frame vibrations can be distinctively reduced by the active control.

The weighting factor influence on the ratio of damping factors is important, as it shows the parametric analysis with a rectangular pulse.

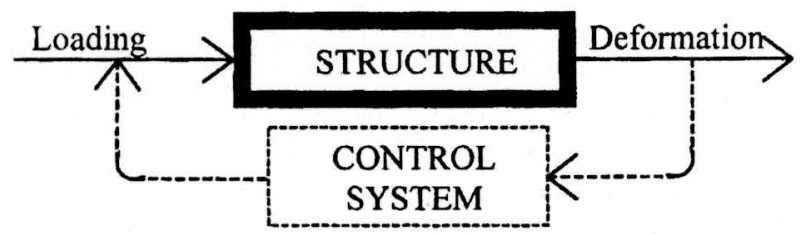

Figure 1. Structural control scheme



Figure 2. Frame with active tendons

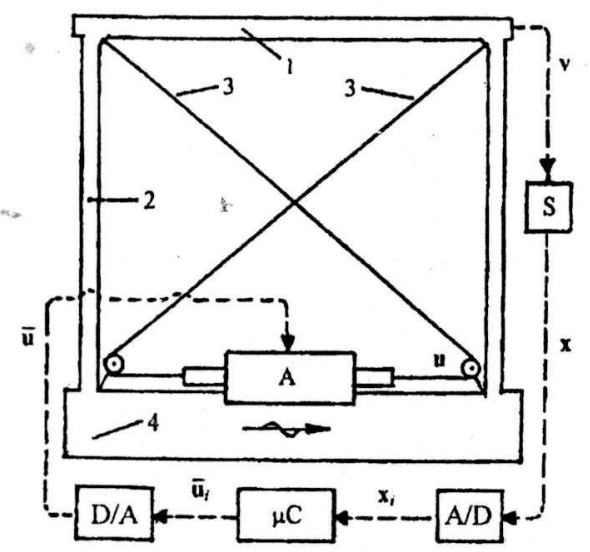

Figure 3. Frame control system, Notation: 1- Beam, 2- Column, 3- Tendon, 4- Foundation; S-Sensor, A/D \& D/A-Converters, $\mu \mathrm{C}$ - Controller (micro computer), A- Actuator

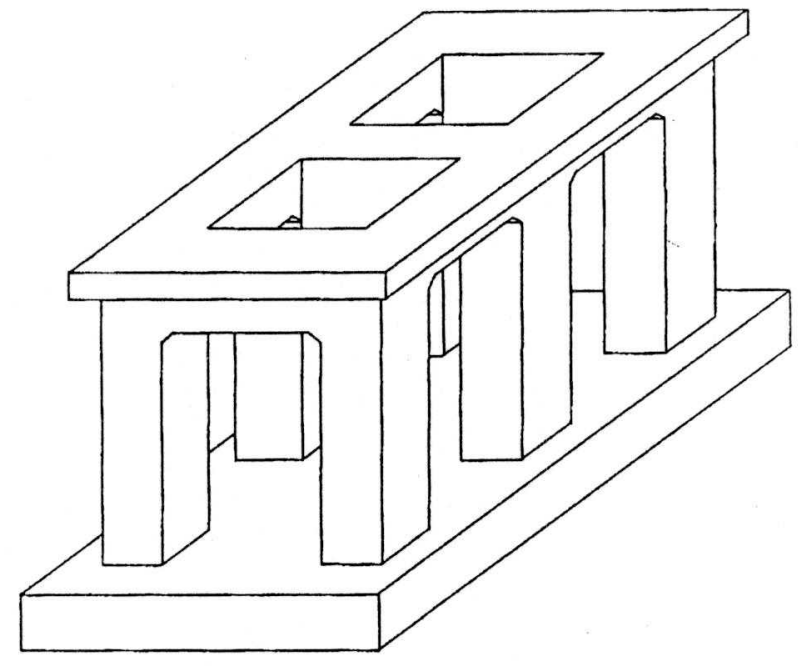

Figure 4. Concrete frame foundation for turbo-alternators

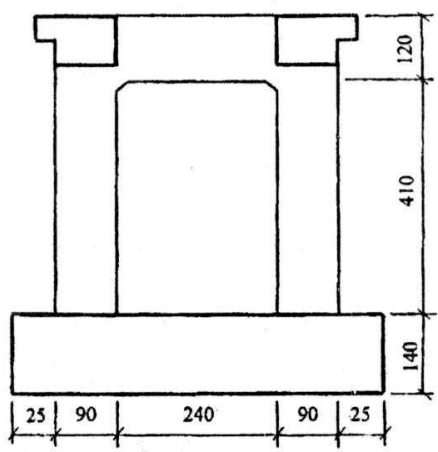

Figure 5. Transversal middle frame of foundation [in $\mathrm{cm}$ ]

Table 1 Parameters of frame dynamic model

\begin{tabular}{|lll|}
\hline Parameter & Value & Unit \\
\hline Mass & $m=550 / 9,81$ & $\mathrm{kN} \mathrm{s}^{2} / \mathrm{m}$ \\
Damping factor & $\zeta=0,01$ & - \\
Stiffness of frame & $k=277960$ & $\mathrm{kN} / \mathrm{m}$ \\
Tendon inclination angle & $\theta=56$ & $\left({ }^{\circ}\right)$ \\
Natural circluar frequency & $\omega=70,41$ & $\mathrm{rad} / \mathrm{s}$ \\
Natural period of frame & $T=0,0892$ & $\mathrm{~s}$ \\
Natural linear frequency & $f=11,21$ & $\mathrm{~Hz}$ \\
Ground acceler. pulse & $\ddot{v}_{g}=1$ & $\mathrm{~m} / \mathrm{s}^{2}$ \\
Pulse duration & $t_{g}=0,1$ & $\mathrm{~s}$ \\
\hline
\end{tabular}

Table 2 Effect of weighting factor $\beta$

\begin{tabular}{|ccccccc|}
\hline$\beta$ & $v_{\max }$ & $t_{v}$ & $u_{\max }$ & $t_{u}$ & $k_{l} / 10^{3}$ & $k_{2} / 10^{3}$ \\
- & {$[\mathrm{mm}]$} & {$[\mathrm{s}]$} & {$[\mathrm{kN}]$} & {$[\mathrm{s}]$} & - & - \\
\hline$\infty$ & $-0,5642$ & 15,168 & - & - & 0 & 0 \\
1 & $-0,2808$ & 11,190 & $-41,229$ & 11,177 & 3,4608 & 12,435 \\
\hline
\end{tabular}




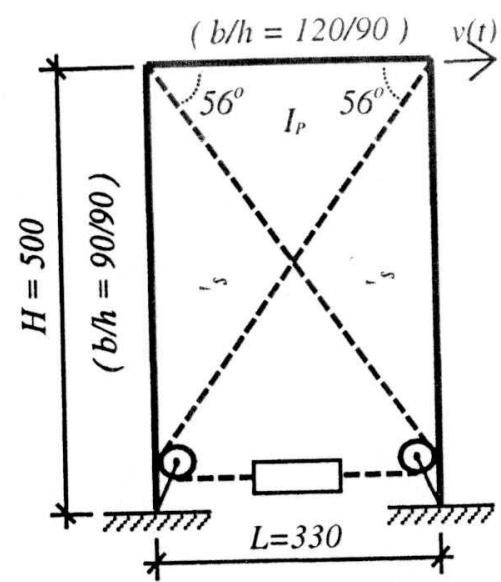

Figure 6. Frame geometry [in $\mathrm{cm}]$



Figure 7. The Petrovac earthquake accelerogram

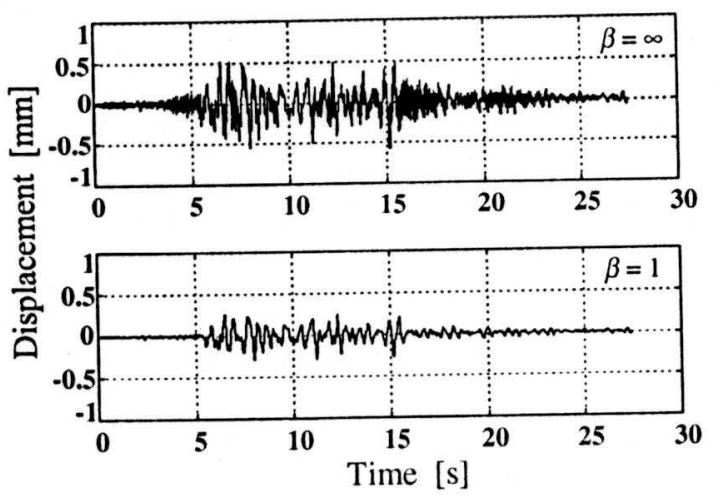

Figure 8. Displacement history

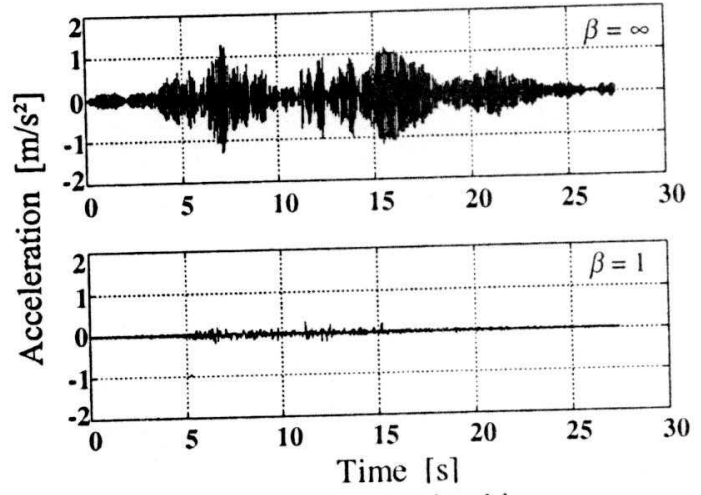

Figure 9. Acceleration history

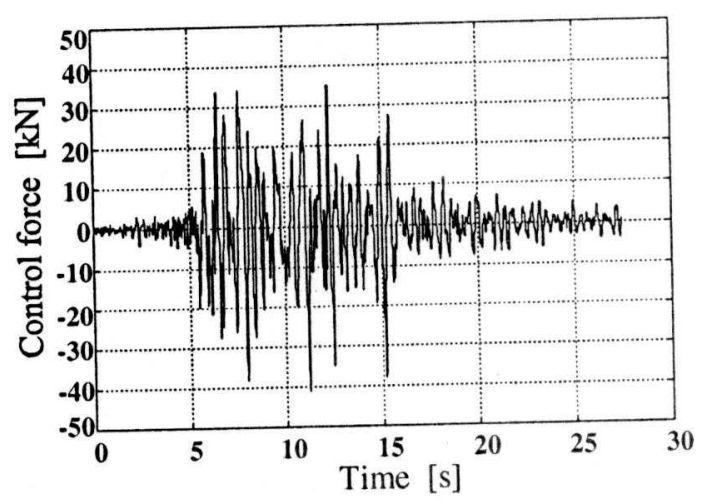

Figure 10. Control force history

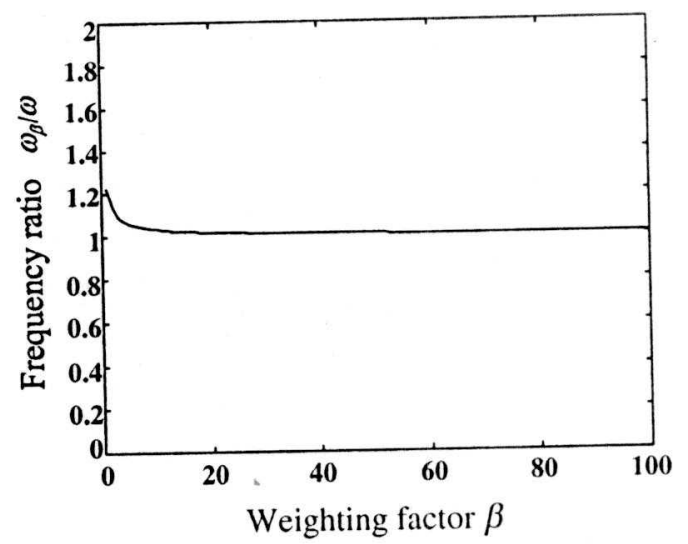

Figure 11. Effect of weighting factor $\beta$ on natural frequency 




Figure 12. Effect of weighting factor $\beta$ on damping

\section{REFERENCES}

[1] Barnett, S. (1975): Introduction to Mathematical Control Theory, Clarendon Press, Oxford.

[2] Beton-Kalender 1979, Taschenbuch für Beton-. Stahlbeton- und Spannbetonbau sowie die verwandten Fächer, (68. Jahrgang), Teil I, Ernst, Berlin, 1979.
[3] Chung. L.L., Reinhorn, A.M., Soong. T.T. (1988): Experiments on Active Control of Seismic Structures, Journal of Engineering Mechanics. ASCE, Vol. 114, No.2, pp. 241-256.

[4] Clough. R.W., Penzien, J. (1975): Drnamics of Structures, McGraw-Hill. New York.

[5] Domke. H., Backé, W., Meyr, H., Hirsch, G.. Goffin, H. (1981): Aktive Verformungskontrolle von Bauwerken, Bauingenieur. H. 56, S.405-412.

[6] Furundzic, S.B, Milutinovic, Lj.D, (1998): Frame Active Control, Proceedings of the 15th ECPD International Conference on Material Handling and Warehousing. Belgrade, pp. 4.53 - 4.57.

[7] Savinov, O.A. (1979): Sorremennye konstrukcii fundamentov pod mashing $i$ ih raschet. (Izdanie 2-e), Stroiizdat, Leningrad.

[8] Spencer, B.F., Sain, M.K. (1997): Controlling Buildings: A New Frontier in Feedback, IEEE Control Systems. Vol. 17. No. 6, pp. 19-35.

[9] Yao, J.T.P. (1972): Concept of Structural Control, Journal of the Structural Division. ASCE. Vol. 98, No. ST7, pp. 1567-1574. 